\title{
A 500 Watts Single Stage Single Switch Soft Switched CCM PFC Flyback Converter with BCM Control
}

\author{
Rayudu Mannam ${ }^{1 *}$, Srinivasa Rao Gorantla ${ }^{2},{ }^{3}$ Nagesh Vangala \\ ${ }^{1}$ Vignan's University, Chirra Engineers Pvt. Ltd. Bangalore 560062 \\ ${ }^{2}$ Vignan's University, Vadlamudi Guntur 522213 \\ ${ }^{3}$ Vignan's University, Chirra Engineers Pvt. Ltd, Bangalore 560062 \\ *Corresponding author E-mail: rayudu@chirra.in
}

\begin{abstract}
:
Single stage isolated AC to DC converters find prominence due to simplicity and efficiency in addition to economics. Boundary control Mode BCM Flyback converters are widely used for such applications up to power levels of 200 watts. For higher power levels, average current control mode PFCs are used and two stage conversion is incorporated. In this paper, a novel technique for building a single stage PFC with a Continuous Conduction Mode CCM Flyback AC DC converter is proposed for 500 watts power. A practicalsingle stage converter is built with power factor correction and input output isolation. The unique feature of the new configuration lies in having only one primary MOSFET switch and adapting BCM control in a CCM Flyback configuration and achieving ZVS and ZCS while in CCM operation. Proposed configuration is best suited for battery charger applications. Also, the absence of high voltage bulk capacitor at the mains input adds lot of advantages in terms of eliminating inrush current and saving PCB area. A working model of $130 \mathrm{~V}$ Dc output and $4.0 \mathrm{~A}$ is built and the test data are presented depicting the complete soft switching of all power devices and exhibiting the efficiencies in excess of $95 \%$.

Keywords: Single Stage, Soft Switching, PFC, Power Factor Correction, Flyback Converter, CCM, BCM Control, Delay, efficiency, power loss
\end{abstract}

\section{Introduction}

As the technology development is rapidly progressing, so is the utility of electrical energy. By the day, the number of electronic gadgets getting in to human lives is progressing at a steady pace. Thereby, in addition to the demand of producing additional energy, a large thrust is imposed on the improvement of energy efficiency of existing/upcoming gadgets and reduction of losses.[1]

The number of electronic gadgets increased imposing international agencies such as EN, VDE and CISPER [2], to define the interface specifications for electronic gadgets connected to utility mains. As a part of the specifications, it is mandatory that all electronic equipment consuming power of 75 watts and more have to meet the power factor requirements and current harmonic distortion levels. The IEC specification IEC 61000-3-2 dictates the requirement of power factor.

\section{Active Power Factor Correction}

Most of the AC DC converters are Offline SMPS, meaning rectifying the $\mathrm{AC}$ input directly with a high voltage bridge rectifier following it up with a large filter capacitor. Under such conditions, current drawn from the mains is spiky and current is drawn for short durations only at the peak of input voltage. So, in the complete one rectified mains switching cycle say 10miiliseconds( For $50 \mathrm{~Hz}$ ), energy is drawn from the input only for a short duration and the rest of the time current is not drawn. Hence, this method turns out to be highly inefficient as most of the time input energy is not utilized. The ratio of peak current to average current is very high, to compensate the idle duration. These adverse factors can be conveniently corrected with active power factor correction.

Since the discontinuous input current has to be made continuous, Boost configuration DC-DC converters are well suited in PFC applications. Boost regulator input current is continuous because the output voltage is higher than the input voltage and load current is always flowing through the input [3].

Active Power Factor Converter power supplies can be classified as two types

a) Two Stage: This involves a front end boost converter which generates a regulated DC voltage of around $400 \mathrm{~V} \mathrm{DC}$, from the rectified mains input voltage. Then a second level DC-DC converter is employed to generate the user needed output voltage with input output galvanic isolation. Variety of control ICs are available to actively correct the input current wave shape and power factor. The two stage PFC circuits are adapted for power levels of above 200 watts. Average input current control technique is used to achieve PFC and mostly the boost converter operates in the continuous conduction mode [8].

b) Single Stage PFC: For power levels of less than 200 watts, single stage PFC converters are in use. These converters achieve good PF and generate the user required low voltage with isolation. Though these units look simple and attractive because of one stage control, they are limited to low power levels. For such applications, Flyback converters with boundary control mode $\mathrm{BCM}$ with constant $\mathrm{ON}$ time are adapted widely in the industry. Umpteen control ICs for such scheme are available for commercial applications $[4,9]$. 
Though there are some configurations, wherein a single MOSFET switch is used for Boost operation and the subsequent DC-DC conversion and categorized as single stage PFC converters for higher power [5], they did not gain much prominence due to two control loops and higher current stress in the single switch. Therefore single stage PFC converters are mostly the Flyback converters operating in the boundary conduction control mode (BCM) which achieve high PF and isolated output. The peak current in a BCM Flyback is very large compared to its average current and hence the limitation of lower power levels. Also, as the current ripple is high, these techniques require a larger line filters. However BCM fly back PFC converters are very popular and as stated earlier large number of control ICs for single stage $\mathrm{PFC}$ is available for industrial use.

Keeping all the above in mind, it is proposed in this paper a new and novel technique to build a single stage PFC AC DC converter with CCM fly back technology ,but with a BCM PFC controller IC. One the major advantage is attaining complete soft switching of all the power devices. Only a single MOSFET switch is used and no extra control algorithm or additional complexity in control is incorporated. A 500 watts converter is built with this scheme. Complete soft switching, a good power factor are demonstrated. The efficiency achieved is in the range of $95 \%$.

\section{Flyback Converters}

A normal fly back converter in CCM control is shown in figure 1 .

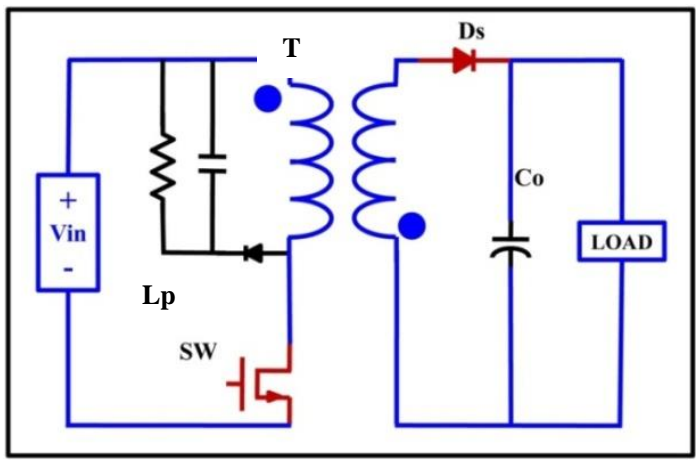

Fig 1: Normal Flyback Converter

MOSFET switch $\mathrm{Sw}$ is $\mathrm{ON}$ for $\mathrm{T}_{\text {on }}$ duration, where in energy is stored in the primary inductance $\mathrm{L}_{\mathrm{p}}$ of the transformer $\mathrm{T}$. During this phase, owing to the polarity, secondary diode $\mathrm{D}_{\mathrm{s}}$ is OFF and output load is supplied by the reservoir capacitor $\mathrm{C}_{0}$ connected across output $\mathrm{V}_{0}$. Sw is OFF for a duration $\mathrm{T}_{\text {off }}$ during which the stored energy in $L_{p}$ is delivered to load after turning $\mathrm{ON}$ the secondary diode. $\mathrm{T}_{\text {on }}+\mathrm{T}_{\text {off }}$ forms the total time duration $(\mathrm{T})$ of the switching frequency. Output voltage is regulated by a controller, varying the duty cycle $\mathrm{D}$ defined as $\mathrm{T}_{\text {on }} / \mathrm{T}$. Volt seconds across $\mathrm{L}_{\mathrm{p}}$ are balanced over a switching cycle as

$\mathrm{V}_{\text {in }} * \mathrm{~T}_{\text {on }}=\mathrm{V}_{0} * \mathrm{~T}_{\text {off }}$ for a $1: 1$ transformer turns ratio

Though we call it the transformer, in reality the fly back transformer is an inductor with two or more windings. Either the primary or the secondary shall be conducting at any given time and hence a DC bias is always present. This demands an air gap to be introduced in the magnetic path leading to increase in the leakage inductance. The energy stored in the leakage inductance can be large enough to destroy the MOSFET switch $\mathrm{Sw}$ if unattended. Therefore in normal Flyback converters, RCD snubber as shown in fig. 1 is incorporated to absorb the leakage energy.

It is very evident from the current and drain voltage waveforms of a CCM fly back converter that the switching is invariably hard in nature and also the snubber adapted is dissipative. This causes reduction in efficiency. Nevertheless, peak currents in the MOSFET are less compared to BCM [6].

$\mathrm{BCM}$ control ensures that at turn $\mathrm{ON}$ the current in switch is zero and hence reduced turn $\mathrm{ON}$ losses. Likewise the reverse recovery problem of the secondary diode $\mathrm{D}_{\mathrm{s}}$ is automatically eliminated because the MOSFET is turned ON only after the diode/secondary current is reduced to zero. In this case peak currents are quite large.

\section{Present Scheme}

It is envisaged to build a CCM Flyback converter so that the peak currents are smaller. However, BCM control is advantageous due to avoidance of turn ON current and reverse recovery issue of output diode. Therefore, we propose a new scheme which is the combination of BCM and CCM. The configuration is shown in figure 2

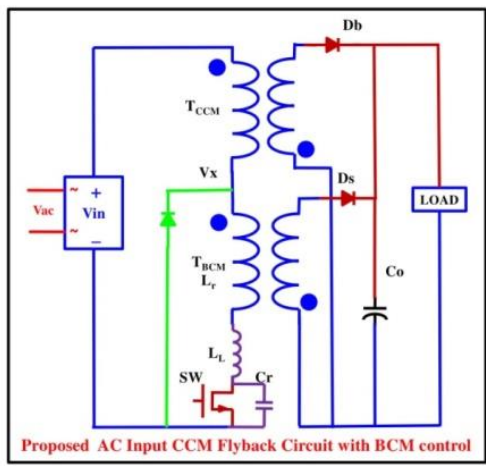

Figure 2: Proposed Configuration

Here in addition to the main Flyback transformer $\left(\mathrm{T}_{\mathrm{CCM}}\right)$, one other resonant Flyback transformer $\left(\mathrm{T}_{\mathrm{BCM}}\right)$ with a primary inductance of $\mathrm{L}_{\mathrm{r}}$ is added and it is made to operate in BCM . Secondaries of both the transformers are tied to output. Resonant Flyback transformer is a step down transformer with primary /secondary turns being " $\mathrm{N}_{\mathrm{B}}$ " and the turns ratio of main transformer is $\mathrm{N}_{\mathrm{C}}$. Turn OFF time of the main switch is dependent on detecting zero current in the resonant Flyback transformer $\mathrm{T}_{\mathrm{BCM}}$ secondary. ON time varies accordingly to regulate the output voltage. The detailed working is described below.

Sequence of achieving soft switching is defined by the following modes of operation of the converter

Mode 1: $\mathrm{Sw}$ is $\mathrm{OFF}$ and the Flyback transformer secondary is supplying the load. $\mathrm{D}_{\mathrm{b}}$ is conducting and current in $\mathrm{L}_{\mathrm{r}}$ is zero. Voltage at $\mathrm{V}_{\mathrm{x}}$ is equal to $\mathrm{V}_{\text {in }}+\mathrm{N}_{\mathrm{C}} \mathrm{V}_{\text {out }}$. $\mathrm{Sw}$ is turned $\mathrm{ON}$ at this instance.

Mode 2: Sw turns $\mathrm{ON}$ with zero current due to $\mathrm{L}_{\mathrm{r}}$. The current in the $\mathrm{Sw}$ and also $\mathrm{L}_{\mathrm{r}}$ begins to rise linearly. This mode ends when the current in the switch reaches $\operatorname{Iin}_{\min } / \mathrm{N}_{\mathrm{C}}$. $\operatorname{Iin}_{\min }$ is the current flowing in the secondary of the Flyback transformer $\mathrm{T}_{\mathrm{CCM}}$ to load.

Mode 3: The diode $D_{b}$ turns OFF with zero current. Current in switch $\mathrm{Sw}$ and $\mathrm{L}_{\mathrm{r}}$ continues rise. This mode ends when the current is switch attains $\operatorname{~Iin}_{\max }$ and the controller turns OFF the switch.

Mode 4: $\mathrm{Sw}$ turns OFF with zero voltage due to $\mathrm{C}_{\mathrm{r}}$. $\operatorname{Iin}_{\max }$ starts charging $\mathrm{C}_{\mathrm{r}}$. Voltage at $\mathrm{C}_{\mathrm{r}}$ gradually rises and this mode ends when it reaches $V_{x}$

Mode 5: At this instance, the current $\operatorname{Iin}_{\max }$ in the primary of flyback transformer is diverted to the output and the energy is transferred to the output. $\mathrm{L}_{\mathrm{r}}$ continues to charge $\mathrm{C}_{\mathrm{r}}$ and this phase ends when the voltage at $C_{r}$ reaches $N_{B} * V_{\text {Out }}+V_{x}$. The time taken for $C_{r}$ to rise from $V_{x}$ to $N_{B} * V_{\text {Out }}+V_{x}$ is much lower than the quarter of the resonant time of $\mathrm{L}_{\mathrm{r}}$ and $\mathrm{C}_{\mathrm{r}}$. 
Mode 6: At this instance the secondary of resonant flyback transformer $\mathrm{T}_{\mathrm{BCM}}$ develops a voltage equal to $\mathrm{V}_{\mathrm{o}}$ and hence diode $\mathrm{D}_{\mathrm{s}}$ conducts. Stored energy in $\mathrm{L}_{\mathrm{r}}$ is transferred to output. This mode ends when the current in secondary of resonant flyback transformer reduces to zero and $D_{s}$ turns off with zero current Thus the energy stored in $\mathrm{L}_{\mathrm{r}}$ due to $\operatorname{Iin}_{\max }$ is divided in to charging $\mathrm{C}_{\mathrm{r}}$ and the balance is transferred to output.

Mode 7: Resonance occurs between $\mathrm{L}_{\mathrm{r}}$ and $\mathrm{C}_{\mathrm{r}}$ and the energy from

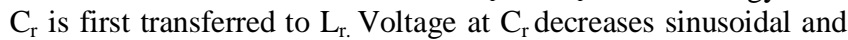
the current in $L_{r}$ builds up. The direction of the current in $L_{r}$ is reversed now. This mode ends when the $C_{r}$ voltage reaches $V_{x}$

Mode 8: At this instance $\mathrm{L}_{\mathrm{r}}$ sees zero voltage across it and the current in $\mathrm{L}_{\mathrm{r}}$ tries to remain constant.

Since $\mathrm{C}_{\mathrm{r}}$ voltage cannot be held constant, it starts decreasing. $\mathrm{L}_{\mathrm{r}}$ starts discharging $\mathrm{C}_{\mathrm{r}}$. If $\mathrm{L}_{\mathrm{r}}$ and $\mathrm{C}_{\mathrm{r}}$ values are properly chosen, then $\mathrm{C}_{\mathrm{r}}$ voltage can reach to zero within the $\mathrm{Sw}$ OFF period. Time taken for the $\mathrm{C}_{\mathrm{r}}$ voltage to come down to zero value starting at $\mathrm{N}_{\mathrm{B}} * \mathrm{~V}_{\text {Out }}+\mathrm{V}_{\mathrm{x}}$ is half the resonant time period of $\mathrm{L}_{\mathrm{r}}$ and $\mathrm{C}_{\mathrm{r} \text {. At this }}$ instance $\mathrm{Sw}$ is turned $\mathrm{ON}$ again by the controller with ZVS and Mode 1 again repeats. The above, in terms of timing chart is explained below in Figure 3:

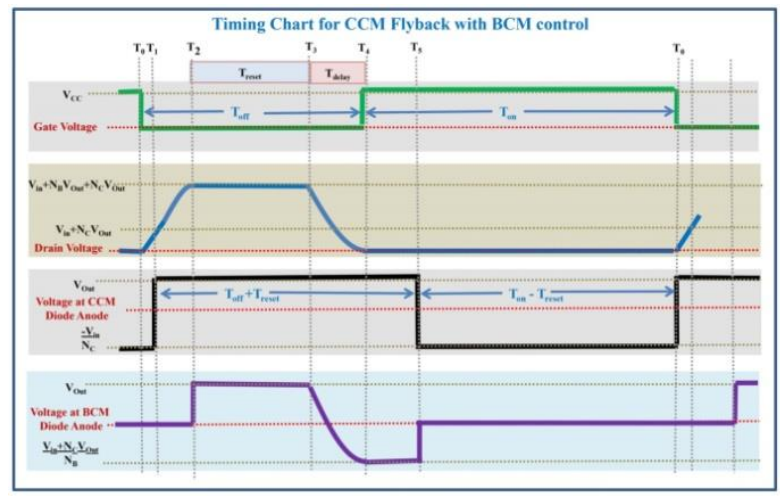

Fig 3: Timing Chart

Prior to $\mathrm{T}_{0}$ the MOSFET switch $\mathrm{Sw}$ was $\mathrm{ON}$ and the diode $\mathrm{D}_{\mathrm{b}}$ was OFF. Load current was supplied by the output capacitor and the input current was $\operatorname{lin}_{\max }$ flowing through the switch, flyback transformer primary and the $\mathrm{L}_{\mathrm{r}}$. At $\mathrm{T}_{0}$ switch $\mathrm{Sw}$ is turned OFF by the controller.

$\mathrm{T}_{0}-\mathrm{T}_{1}$ : Due to the capacitor $\mathrm{C}_{\mathrm{r}}$, MOSFET turns OFF with zero voltage and the current $\operatorname{~in}_{\max }$ gradually charges the $\mathrm{C}_{\mathrm{r}}$ and the drain voltage starts rising. At $\mathrm{T}_{1}$ the drain voltage reaches the value $\mathrm{V}_{\mathrm{x}}$, the input voltage plus $\mathrm{N}_{\mathrm{C}} * \mathrm{~V}_{\text {Out }}$. At this point, the current in the $\mathrm{T}_{\mathrm{CCM}}$ primary $\operatorname{lin}_{\max }$ gets diverted to the output, by turning $\mathrm{ON}$ the $\mathrm{D}_{\mathrm{b}}$ diode. This duration can be approximated to linear rise in voltage due to large value of inductances and considering them as current sources.

$\mathrm{T}_{1}-\mathrm{T}_{2}$ : In this duration, the resonance occurs between $\mathrm{L}_{\mathrm{r}}$ and $\mathrm{C}_{\mathrm{r}}$ and the drain voltage starts building up further due to the energy transfer from $L_{r}$ in to $C_{r}$. This increase can happen till the energy in $\mathrm{L}_{\mathrm{r}}$ reaches to zero value and the drain voltage reaches a peak value. Maximum value attainable at $C_{r}$ over and above $V_{x}$ is given by

$\operatorname{Iin}_{\max } * \sqrt{ }\left(\mathrm{L}_{\mathrm{r}} / \mathrm{C}_{\mathrm{r}}\right)$

However by design when $C_{r}$ voltage reaches $V_{x}+N_{B} V_{\text {Out }}$, the diode $D_{s}$ conducts and clamps the drain voltage to $V_{x}+N_{B} V_{\text {Out }}$ at $\mathrm{T}_{2}$. This time duration shall be less than one quarter of resonant time period of $\mathrm{L}_{\mathrm{r}}$ and $\mathrm{C}_{\mathrm{r}}$ and is given by equation

$$
\left.(\square / 180) * \sqrt{ }\left(\mathrm{L}_{\mathrm{r}} * \mathrm{C}_{\mathrm{r}}\right) * \operatorname{Sin}^{-1} \mathrm{~N}_{\mathrm{B}} \mathrm{V}_{\text {Out }} /\left(\operatorname{Iin}_{\max } \sqrt{ }\left(\mathrm{L}_{\mathrm{r}} / \mathrm{C}_{\mathrm{r}}\right)\right)\right)
$$

Denoting this as $t_{c h}$ it can be approximated to about $5 \%$ of the resonant period of $\mathrm{L}_{\mathrm{r}}$ and $\mathrm{C}_{\mathrm{r}}$

$T_{2}-T_{3}$ : During this period the balance energy in $L_{r}$ is transferred to the output. At $T_{3}$, the energy in the $L_{r}$ is completely depleted and therefore the Zero Current Detection ZCD, signal changes its state from HIGH to LOW. This duration is titled as $\mathrm{T}_{\text {reset }}$ and is determined by $\mathrm{V}_{\text {Out }}, \mathrm{N}_{\mathrm{B}}, \mathrm{I}_{\text {inmax }}$ and $\mathrm{L}_{\mathrm{r}}$. $\mathrm{T}_{\text {reset }}$ is approximated as $\mathrm{L}_{\mathrm{r}} * \operatorname{Iin}_{\mathrm{max}} \cdot / \mathrm{V}_{\text {Out }} * \mathrm{~N}_{\mathrm{B}}$

$\mathrm{T}_{3}-\mathrm{T}_{4}$ : In a normal boundary mode controller operation, the MOSFET switch Sw is turned ON immediately, the moment ZCD signal changes its state from HIGH to LOW. But, in the proposed technique, a deliberate delay $\mathrm{t}_{\text {delay }}$ is introduced in turning $\mathrm{ON}$ the $\mathrm{Sw}$ after ZCD changes its state. The reason is explained here. At $\mathrm{T}_{3}$, the complete energy in transformer is depleted and the drain voltage at $C_{r}$ is $V_{x}+N_{B} V_{\text {out }}$. The resonance starts between $L_{r}$ and $C_{r}$ at this point, because the MOSFET is still OFF and controller has not yet sent the ON signal. Drain voltage starts decreasing sinusoidally due to energy transfer from $\mathrm{C}_{\mathrm{r}}$ to $\mathrm{L}_{\mathrm{r}}$. After drain voltage reaches $V_{x}, L_{r}$ takes over and starts discharging $C_{r}$ further.

The drain voltage will reach to zero value at $\mathrm{T}_{4}$ and the duration of $\mathrm{T}_{4}$ toT $_{3}$ is exactly the half resonant time period of $\mathrm{L}_{\mathrm{r}}$ and $\mathrm{C}_{\mathrm{r}}$. The delay time $t_{\text {delay }}$ is set to this half resonant time so that the controller turns $\mathrm{ON}$ the MOSFET at $\mathrm{T}_{4}$. This achieves the Zero voltage switching for the main switch . The switch OFF time $T_{\text {off }}$ is fixed as $\mathrm{T}_{0}$ to $\mathrm{T}_{4}$. It is to be noted that at $\mathrm{T}_{4}$ when the switch is turned $\mathrm{ON}$, the current in the $\mathrm{L}_{\mathrm{r}}$ is zero and therefore the switch Sw turns ON with zero current, even though the diode $D_{b}$ is still conducting and the current in flyback transformer $\mathrm{T}_{\mathrm{CCM}}$ secondary

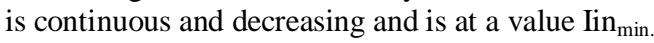

The ON time of the boost switch can be determined by applying the Volt second balance across the primary of flyback transformer.

Broadly, the $\mathrm{T}_{\text {off }}$ almost can be termed to be fairly constant (though it slightly varies depending on the load current) but $T_{\text {on }}$ varies largely with line and load, to maintain the total soft switching and regulating the output voltage.

\section{Implementation}

The following design equations ensure the ZVS and ZCS for the main boost switch while operating in the continuous conduction mode. Prime facilitator for this is in maintaining approximately constant OFF time and allowing the switching frequency as a variable component.

$\mathrm{V}_{\text {in }}$ is the input DC voltage, $\mathrm{V}_{\text {Out }}$ is the output,

Applying volt seconds balance for Flyback transformer,

$\mathrm{V}_{\text {Out }} *\left(\mathrm{~T}_{\text {off }}+\mathrm{T}_{\text {reset }}\right)=\mathrm{V}_{\text {in }} *\left(\mathrm{~T}_{\text {on }}-\mathrm{T}_{\text {reset }}\right) / \mathrm{N}_{\mathrm{C}} \ldots \ldots \ldots$

$\mathrm{T}_{\text {reset }}$ Is approximated to $\mathrm{L}_{\mathrm{r}} * \operatorname{Iin}_{\max } \cdot / \mathrm{V}_{\text {Out }} * \mathrm{~N}_{\mathrm{B}} \ldots$

$\mathrm{T}_{\text {off }}=\mathrm{T}_{\text {reset }}+1.1 \square \sqrt{ } \mathrm{L}_{\mathrm{r}} * \mathrm{C}_{\mathrm{r}}$

$\mathrm{C}_{\mathrm{r}}$ is computed by holding the drain voltage to a low value during the turn off duration of the switch $\mathrm{Sw}$ with the $\mathrm{Iin}_{\max }$ current.

A practical proto type AC DC converter was built with the above technique. Converter input was designed to be either 190V AC$260 \mathrm{~V}$ AC volts or $190 \mathrm{~V}$ DC to $300 \mathrm{~V}$ DC. Output was rated for $130 \mathrm{~V}$ DC at 4.0Amps load. The BCM PFC controller IC FAN 7527 was used for control. All the fast recovery diodes were MUR860, and the Mosfet switch was a 1200V rated device. This scheme incorporates a variable switching frequency to achieve soft switching of all the components. The proto type designed and fabricated was not provided with any line filter and the input current captured is without any line filter. The proto unit was 
tested to its full capacity and even heat run test was conducted at ambient temperature to record the temperature rise of power components.

\section{Results and Discussion}

The complete test data such as efficiency, PF and THD are reported. Efficiency measurements and also the gate and drain waveforms are captured for DC input to depict soft switching clearly. Fig.4 depicts the zero voltage turn ON and OFF distinctly at full load condition. The absence of Miller effect in the gate drive further emphasises the ZVS condition.

Table 1: Efficiency at Various Line and Load Conditions

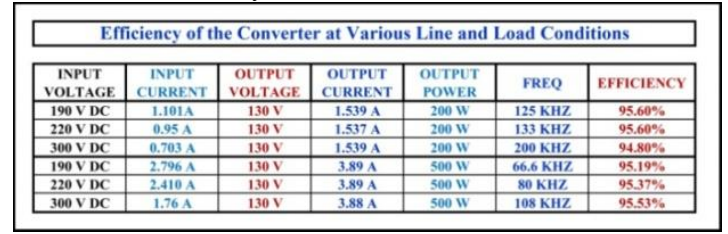

Table 2: PF and THD at Various Line and Load Conditions

\begin{tabular}{|c|c|c|c|c|}
\hline \multicolumn{5}{|c|}{ Power Factor and Harmonic Distortion Data } \\
\hline \multirow{2}{*}{$\begin{array}{c}\text { INPUT } \\
\text { VOLTAGE } \\
\end{array}$} & \multicolumn{2}{|c|}{200 WATTS } & \multicolumn{2}{|c|}{ 500 WATTS } \\
\hline & PF & THD \% & PF & THD \\
\hline $190 \mathrm{~V} A C$ & 0.994 & $4.2 \%$ & 0.999 & $12.2 \%$ \\
\hline $220 \mathrm{~V}$ AC & 0.990 & $5.8 \%$ & 0.998 & $10.3 \%$ \\
\hline $260 \mathrm{~V} A C$ & 0.979 & $6.1 \%$ & 0.997 & $8.5 \%$ \\
\hline
\end{tabular}

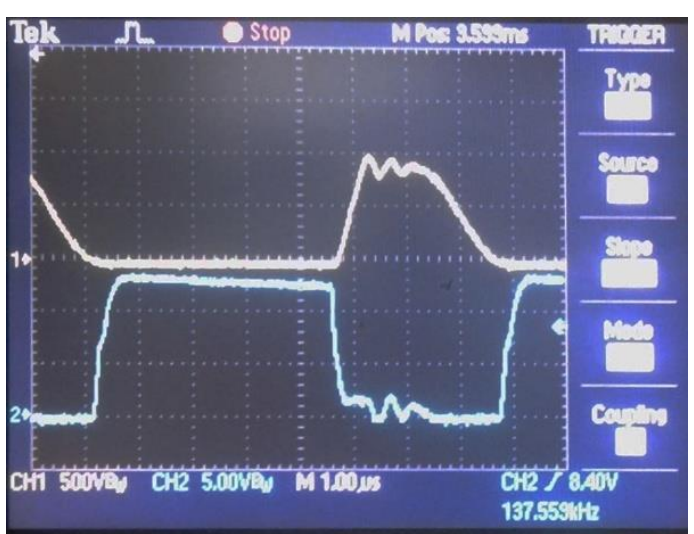

Fig. 4: Gate and Drain full Waveform At 220 V AC input 500W Load

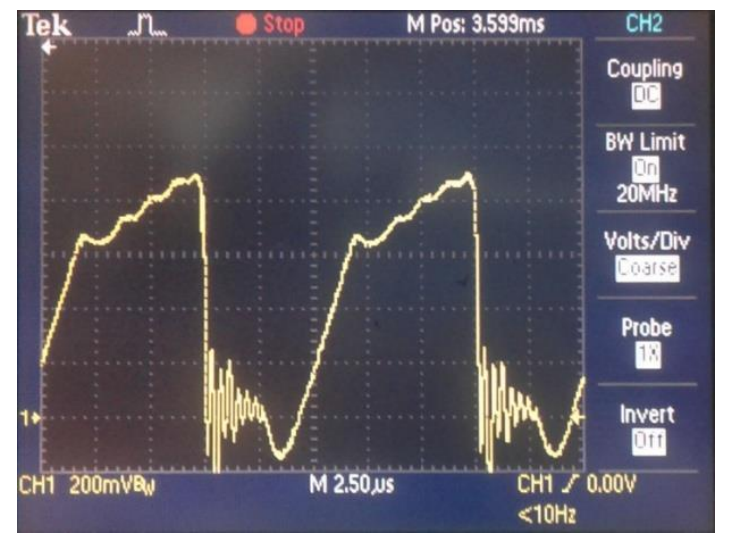

Fig. 5: Drain Current Waveforms At 220 V DC Input 500W Load

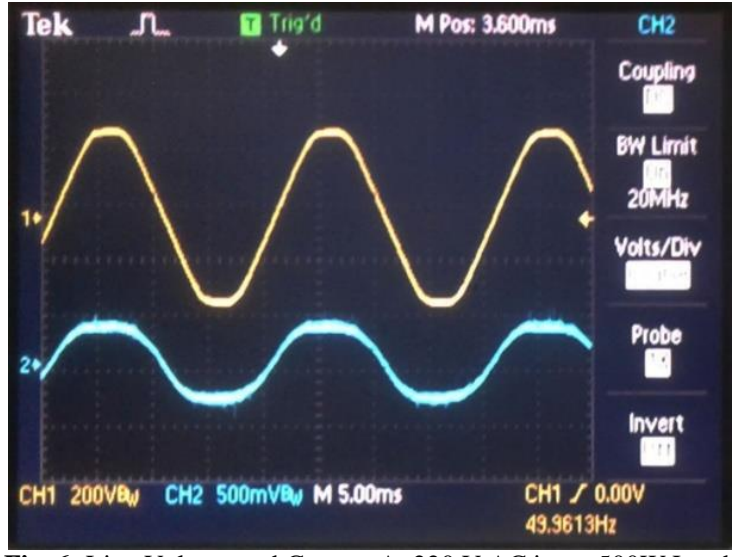

Fig. 6: Line Voltage and Current At 220 V AC input 500W Load

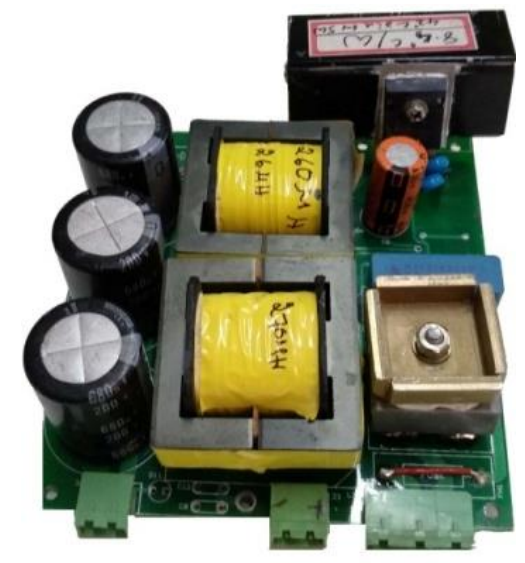

Fig.7: Product Image

The switch current shown in fig 5 demonstrates CCM mode of operation. At turn $\mathrm{ON}$, zero current is seen and the initial slow rise has the slope due to $\mathrm{L}_{\mathrm{r}}$ and the second slope is due to the primary inductance of $\mathrm{T}_{\mathrm{CCM}}$. The fact that $\mathrm{D}_{\mathrm{b}}$ also turns $\mathrm{OFF}$ with zero current is established. Fig 6 depicts the input current obtained for an AC input voltage of $220 \mathrm{~V}$ AC and full load at output. The input current is near sinusoidal and it contains no high frequency component which gives thrust that the unit is in CCM and current ripple is low.Table1, reports efficiency figures achieved at various input levels for 200 and 500watt output. Results are very encouraging and clearly demonstrate the advantages of this scheme. Further Table 2 demonstrates the power factor and THD achieved for various input and output conditions. These measurements were conducted with Yokogowa WT210 power analyzer. The unit was run at full load continuously with natural convection cooling till the thermal equilibrium was obtained to estimate the power losses in transformers and the MOSFET switch.

MOSFET was mounted on a calibrated heat sink with thermal resistance of $8.4^{\circ} \mathrm{C}$ per watt. The thermal resistance of the transformers were taken as $18^{\circ} \mathrm{C}$ per watt from the data sheet. The estimated power loss in each of the transformer was around 3.5 watts and the Mosfet dissipated around 3watts.It is pertinent to mention here that the envisaged scheme demands a higher voltage Mosfet in the range of $1200 \mathrm{~V}$ for $230 \mathrm{~V}$ AC operation and $130 \mathrm{~V}$ DC output. The turns ratio $\mathrm{N}_{C}$ was chosen as Unity and $\mathrm{N}_{B}$ was 3.3 for $130 \mathrm{~V} \mathrm{DC}$ output [7]. Fig 7 shows the image of the fabricated product.

\section{Conclusions}

A new technique is proposed to achieve total soft switching in a CCM flyback converter for power levels in the range of 500 
Watts. A single switch, single stage, power factor corrected 500 watts converter is fabricated with the proposed scheme and the test data obtained are presented. Efficiency was around $95 \%$ and the PF was above 0.99. Total soft switching of all the switching devices is demonstrated. The simplicity and compactness of the present scheme can be comprehended by comparing the proposed one with already published literature [10]

\section{References}

[1] Global Energy Transformation, A Road Map to 2050, IRENA 2018

[2] IEC,2010, Harmonic Current Emissions Guidelines to the standard EN 61000-3-2

[3] Miao-miao Cheng, Zhiguo Liu, YueyueBao, and Zhongjie Zhang , 2016, Continuous Conduction Mode Soft-Switching Boost Converter and its Application in Power Factor Correction Journal of Power Electronics, Vol. 16, No. 5, pp. 1689-1697

[4] ON Semiconductor, 2014Power Factor Correction (PFC) Handbook, Choosing the Right Power Factor Controller Solution, Rev. 5

[5] Yeong-Chang Yan, et al, 2009 A Single-stage Soft-Switching Flyback Converter for Power-Factor-Correction Applications, Vehicle Power and Propulsion Conference,. VPPC '09, IEEE Dearborn, MI, USA 1412 -1415.

[6] Abraham Pressman, Keith Billings, Taylor Morey, Switching Power supply Design, Third edition Mc Graw Hill, 2009

[7] Nagesh Vangala, Rayudu Mannam, Transformer Design to Achieve Soft Switching In Low Power Flyback Converters, IEEE 1st International Conference on Power Electronics, Intelligent Control and Energy Systems (ICPEICES 2016) held at Delhi Technological University, New Delhi, India, during 4th to 6th July 2016

[8] Chushan Li, Yu Zhang, and David Xu, Soft switching Single stage Isolated AC DC converter for single phase high power Pfc applications. 9th International Conference on Power ElectronicsECCE Asia June 1 - 5, 2015, 63 Convention Center, Seoul, Korea

[9] AND8147/D, ON semiconductor Application note, An Innovative Approach to Achieving Single Stage PFC and Step-Down Conversion for Distributive Systems, 2011

[10] Yeong-Chang Yan, Shih-Jen Cheng,et al , Shann-Chyi Mou., A single stage Soft switching Flyback Converter for Power factor correction Applications. 2009 IEEE Vehicle Power and Propulsion Conference, 7-10 Sept. 2009 